\title{
Unintended consequences of delisting routine eye exams on retinopathy screening for people with diabetes in Ontario, Canada
}

\author{
Tara Kiran MD MSc, Alexander Kopp BA, Rahim Moineddin PhD, J. Charles Victor MSc PStat, \\ Robert J. Campbell MD MSc, Baiju R. Shah MD PhD, Richard H. Glazier MD MPH
}

\begin{abstract}
Background: Routine eye examinations for healthy adults aged 20-64 years were delisted from the Ontario Health Insurance Plan in 2004, but they continue to be insured for people with diabetes regardless of age. We sought to assess whether the delisting of routine eye examinations for healthy adults had the unintended consequence of decreasing retinopathy screening for adults with diabetes.
\end{abstract}

Methods: We used administrative data to calculate eye examinations for people with diabetes ages 40-64 years and 65 years and older in each 2-year period from 1998 to 2010. We examined differences by sex, income, rurality and type of health care provider. We used segmented linear regression to assess the change in trend before and after 2004.

Results: For people with diabetes aged 65 years and older, eye examinations rose gradu- ally from 1998 to 2010, with no substantial change between 2004 and 2006. For people with diabetes aged 40-65 years, there was an $8.7 \%$ (95\% confidence interval [ $\mathrm{Cl}] 6.3 \%-$ $11.1 \%$ ) decrease in eye examinations between 2004 and 2006. Results were similar for all population subgroups. Ophthalmologic examinations decreased steadily for both age groups during the study period, and there was a decline in optometry examinations for people ages 40-65 years after 2004.

Interpretation: The delisting of routine eye examinations for healthy adults in Ontario had the unintended consequence of reducing publicly funded retinopathy screening for people with diabetes. More research is needed to understand whether patients are being charged for an insured service or to what degree misunderstanding has prevented patients from seeking care.
$\mathrm{D}$ iabetic retinopathy is the leading cause of new cases of blindness in people of working age. ${ }^{1}$ In the United States, about $40 \%$ of adults with diabetes aged 40 years and older have retinopathy, and $8 \%$ have visionthreatening retinopathy. ${ }^{2}$ Studies suggest that, if untreated, $50 \%$ of patients with proliferative diabetic retinopathy become legally blind within 5 years, compared with only $5 \%$ of patients who receive early treatment. ${ }^{3}$ Regular dilated eye examinations are effective for early detection and monitoring of asymptomatic retinopathy in people with diabetes ${ }^{4}$ and are recommended by clinical practice guidelines. ${ }^{5,6}$

In Ontario, Canada's most populous province, medically necessary services are covered by the Ontario Health Insurance Plan (OHIP) for all permanent residents and Canadian citizens living in the province. ${ }^{7}$ Under OHIP, routine eye examinations were fully insured for all children and adults until November 1, 2004. At that time, rou- tine eye examinations ceased being insured for healthy adults aged 20-64 years, but continued to be insured for children aged 19 years and younger and for adults aged 65 years and older. ${ }^{8}$ Regardless of age, adults with diabetes and some other medical conditions affecting the eye, as well as adults receiving social assistance, continued to have an annual eye examination covered by OHIP. Insured examinations are at no cost to the patient and are reimbursed to the provider at about Can $\$ 40$. In contrast, healthy adults aged 20-64 years are required to pay out-of-pocket or through private insurance for a routine eye examination, with fees set at the discretion of the optometrist $^{9}$ or physician. ${ }^{10}$

Health policy experts suggest that delisting services from insurance schemes can have unpredictable effects. ${ }^{11}$ Understanding the effect of delisting on care is particularly important as governments face fiscal pressures and contemplate further reductions in what is publicly insured. ${ }^{12}$
Competing interests: None declared.

This article has been peer reviewed.

Correspondence to:

Tara Kiran,

tara.kiran@utoronto.ca

CMAJ 2013. DOI:10.1503 /cmaj.120862 
We sought to assess whether delisting routine eye examinations for healthy middle-aged adults in Ontario had the unintended consequence of decreasing retinopathy screening for middleaged adults with diabetes, even though eye examinations continued to be insured for this population.

\section{Methods}

We used available administrative claims data to conduct a longitudinal analysis of the percentage of Ontario residents with diabetes aged 40 years and older who had at least 1 retinal eye examination in the previous 2 years, as recommended by clinical practice guidelines. ${ }^{6}$ Data were accessed through a comprehensive research agreement with the Ontario Ministry of Health and LongTerm Care. Before the data were analyzed, all patient and provider identifiers were removed and replaced with unique encrypted numbers. The study was approved by the Research Ethics Board of Sunnybrook Health Sciences Centre in Toronto, Ontario.

\section{Data sources}

We identified people with diabetes aged 40 years and older using the Ontario Diabetes Database, a registry of Ontario patients with a diagnosis of diabetes generated using a validated administrative data algorithm. ${ }^{13}$ Patient age, sex and place of residence were obtained from the Registered Persons Database, the registry for all people covered by OHIP. We derived neighbourhood income quintiles by linking data from the 2006 Canadian census to the patients' residential postal codes. We assessed rurality using the Rurality Index of Ontario. ${ }^{14}$ We determined receipt of a retinal eye examination using optometry and physician service claims to OHIP; however, examinations that were paid for privately were not captured. We assessed other diabetes testing (cholesterol and glycated hemoglobin) using laboratory service claims to OHIP.

\section{Analysis}

We calculated the numbers and percentages of patients receiving eye examinations in Ontario using diabetes prevalence for each 2-year period from 1998 to 2010 and stratified our analysis by age ( $<65 \mathrm{yr}, \geq 65 \mathrm{yr})$, sex, income quintile and rurality. We also assessed rates of eye examination over time by type of health care provider (optometrist v. physician). We compared changes in rates of eye examinations over time to changes in rates of other recommended diabetes testing (cholesterol and glycated hemoglobin) in Ontario during the same period. In addition, we compared changes in eye examination rates in Ontario with published changes in ophthalmologic examination rates from another Canadian province, Alberta, ${ }^{15}$ where optometry services were delisted in 1995 for residents aged 19-64 years, then relisted for patients with diabetes in 2007.

We used segmented linear regression models ${ }^{16}$ to assess the change in trend before and after delisting in 2004. Our models allowed a linear trend before 2004 and a linear or quadratic trend after the intervention (Appendix 1, available at www.cmaj .ca/lookup/suppl/doi:10.1503/cmaj.120862/-/DC1). When necessary, we used log transformations to approximate a linear trend before the intervention.

\section{Results}

The number of people with diabetes in Ontario aged 40 years and older increased from 331026 in 1998 to 851193 in 2010 (Tables 1 and 2).

Among people aged 65 years and older, eye examinations rose gradually, from $73.4 \%$ in 1998 to $78.8 \%$ in 2010 (Figure 1). For residents of Ontario aged 40-65 years, the rates remained steady at $69.2 \%$ from 1998 to 2004 , but decreased to $61.1 \%$ in 2006 and remained low at $57.3 \%$ in 2010 (Figure 1). For both age groups, cholesterol and glycated hemoglobin testing rose steadily from 1998 to 2010 (Figure 1).

From 1998 to 2004, there was a gradual increase in eye examinations done by optometrists in Ontario (Figure 2). After 2004, these rates continued to increase gradually for residents aged 65 years and older, but they dropped steeply for those aged $40-65$ years. There was a gradual decrease in eye examinations done by physicians in Ontario from 1998 to 2010. About 98\% of physician eye examinations in Ontario were billed by ophthalmologists, with the rest being billed by general practitioners. For comparison, we looked at published data from Alberta from 1998 to $2008,{ }^{15}$ where there was a gradual decrease over time in eye examinations done by ophthalmologists (Figure 2).

Overall, there was a trend toward a larger decrease in eye examinations after 2004 for residents of Ontario in higher income quintiles than for those in lower income quintiles (Figure 3). From 1998 to 2004, people in the highest income quintiles had more eye examinations than their peers in lower income quintiles (Figure 3). By 2010, this association persisted for people aged 65 years and older, but it was reversed for those less than 65 years of age (Figure 3 ).

Between 2002 and 2004, there was no significant change in the rates of eye examinations for either age group (Table 3). Between 2004 and 2006, there was no significant change in rate for 
Ontario residents aged 65 years and older, but there was an $8.7 \%$ decrease $(95 \%$ confidence interval $[\mathrm{CI}]-11.2 \%$ to $-6.3 \%$ )) in eye examinations for Ontario residents under 65 years of age (Table 3). During the same period, there was no decrease in cholesterol or glycated hemoglobin testing for people in this age group (Table 3).

Between 2004 and 2006, there was a 3.2\% increase (95\% CI $2.6 \%$ to $3.7 \%$ ) in eye examinations by optometrists for Ontario residents aged

Table 1: Characteristics of patients with diabetes in 1998 and 2010, by age group

\begin{tabular}{|c|c|c|c|c|}
\hline \multirow[b]{3}{*}{ Characteristic } & \multicolumn{4}{|c|}{ Patients with diabetes, no. (\%) } \\
\hline & \multicolumn{2}{|c|}{$\begin{array}{c}1998 \\
n=331026\end{array}$} & \multicolumn{2}{|c|}{$\begin{array}{c}2010 \\
n=851193\end{array}$} \\
\hline & $\begin{array}{c}40-64 \mathrm{yr} \\
n=153266\end{array}$ & $\begin{array}{c}\geq 65 y r \\
n=177760\end{array}$ & $\begin{array}{c}40-64 \mathrm{yr} \\
n=413240\end{array}$ & $\begin{array}{c}\geq 65 \mathrm{yr} \\
n=437953\end{array}$ \\
\hline Women & $66483(43.4)$ & 92234 (51.9) & $187171(45.3)$ & $218861(50.0)$ \\
\hline Men & $86783(56.6)$ & $85526(48.1)$ & $226069(54.7)$ & $219092(50.0)$ \\
\hline \multicolumn{5}{|l|}{ Income quintile } \\
\hline 1 (lowest) & 35777 (23.3) & $41003(23.1)$ & $91425(22.1)$ & 94579 (21.6) \\
\hline 2 & $32662(21.3)$ & $39088(22.0)$ & $87725(21.2)$ & $95417(21.8)$ \\
\hline 3 & $30588(20.0)$ & $36521(20.5)$ & $82923(20.1)$ & 86881 (19.8) \\
\hline 4 & $27825(18.2)$ & 30847 (17.4) & 79289 (19.2) & $83197(19.0)$ \\
\hline 5 (highest) & $24272(15.8)$ & $28544(16.1)$ & 66923 (16.2) & $74450(17.0)$ \\
\hline \multicolumn{5}{|l|}{ Residence } \\
\hline Major urban & $107079(69.8)$ & $119366(67.2)$ & $298642(72.3)$ & $303687(69.3)$ \\
\hline Non-major urban & $28682(18.7)$ & $37820(21.3)$ & $74596(18.1)$ & $89816(20.5)$ \\
\hline Rural & 13558 (8.8) & $17714(10.0)$ & 31649 (7.7) & $38700 \quad(8.8)$ \\
\hline
\end{tabular}

Table 2: Characteristics of patients with diabetes who received eye examinations, by year and by age group

\begin{tabular}{|c|c|c|c|c|}
\hline \multirow[b]{3}{*}{ Characteristic } & \multicolumn{4}{|c|}{ Patients who received eye examinations, \% } \\
\hline & \multicolumn{2}{|c|}{$\begin{array}{c}1998 \\
n=236487\end{array}$} & \multicolumn{2}{|c|}{$\begin{array}{c}2010 \\
n=581978\end{array}$} \\
\hline & $\begin{array}{c}40-64 y^{*} \\
n=106001\end{array}$ & $\begin{aligned} & \geq 65 y r^{*} \\
n & =130486\end{aligned}$ & $\begin{array}{c}40-64 y^{*} \\
n=236940\end{array}$ & $\begin{aligned} & \geq 65 \mathrm{yr}^{*} \\
n & =345038\end{aligned}$ \\
\hline Overall & 69.2 & 73.4 & 57.3 & 78.8 \\
\hline Women & 72.9 & 74.0 & 59.4 & 79.0 \\
\hline Men & 66.2 & 72.8 & 55.6 & 78.6 \\
\hline \multicolumn{5}{|l|}{ Income quintile } \\
\hline 1 (lowest) & 66.5 & 71.2 & 58.4 & 76.4 \\
\hline 2 & 68.1 & 72.6 & 57.9 & 78.7 \\
\hline 3 & 70.1 & 74.1 & 57.9 & 79.5 \\
\hline 4 & 71.3 & 74.6 & 57.4 & 80.1 \\
\hline 5 (highest) & 72.6 & 76.9 & 56.1 & 81.1 \\
\hline \multicolumn{5}{|l|}{ Residence } \\
\hline Major urban & 68.6 & 72.8 & 56.1 & 77.6 \\
\hline $\begin{array}{l}\text { Nonmajor } \\
\text { urban }\end{array}$ & 71.1 & 75.5 & 61.4 & 82.6 \\
\hline Rural & 71.3 & 75.6 & 62.4 & 81.7 \\
\hline
\end{tabular}


65 years and older, and a $6.5 \%$ decrease $(95 \%$ CI $-18.0 \%$ to $5.1 \%$, Table 3 ) for Ontario residents aged $40-65$ years. Our secondary analysis

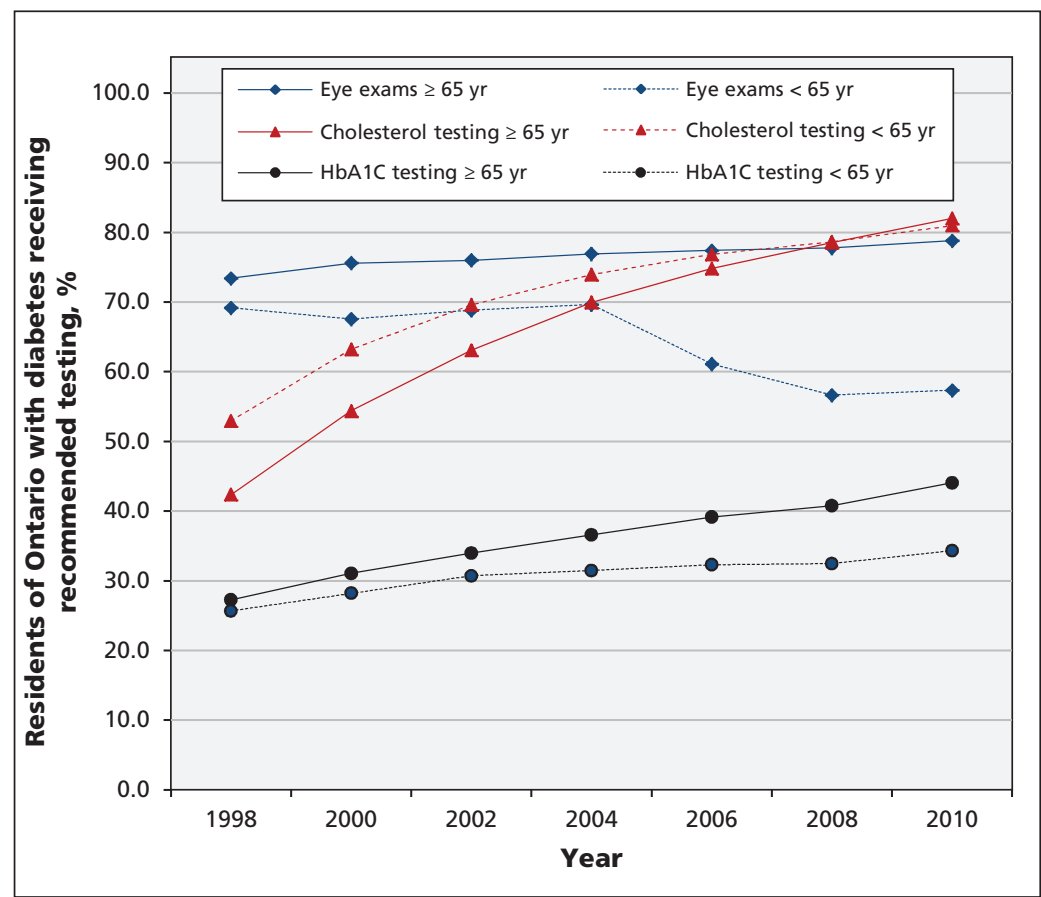

Figure 1: Percentage of Ontario residents with diabetes, by age group, receiving recommended testing (i.e., 1 eye examination, 1 cholesterol test and 4 glycated hemoglobin tests within 2 years) from 1998 to 2010 . HbA1C = glycated hemoglobin.

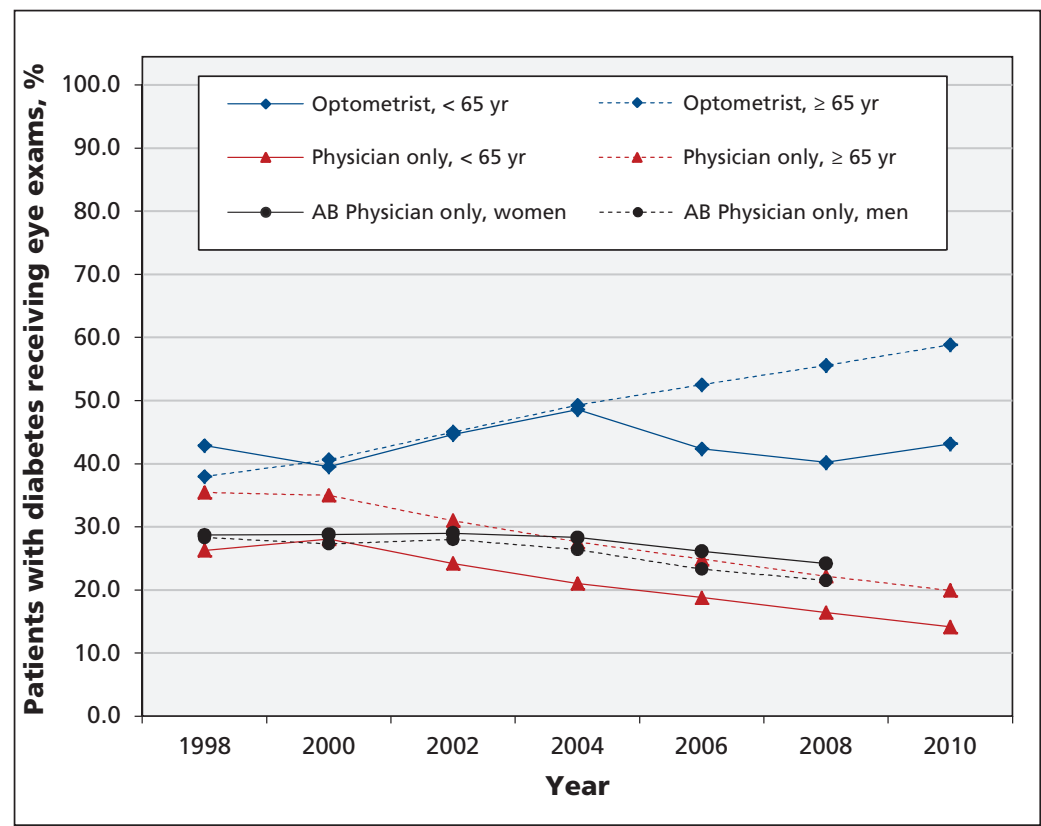

Figure 2: Percentage of Ontario residents with diabetes, by age group, who received an eye examination within a 2-year period from 1998 to 2010, either from an optometrist or a physician. Published data from Alberta are included for comparison (1998-2008). ${ }^{15}$ Data from Ontario assess whether patients aged 40 years and older received an eye examination within a 2-year period; $98 \%$ of physician visits in Ontario were to an ophthalmologist. Data from Alberta assess whether patients with diabetes aged 20 years and older received an eye examination within a 1-year period; only visits to ophthalmologists are included. $A B=$ Alberta. excluded the optometry examinations from 1998 to better approximate a linear trend before 2004. Between 2004 and 2006, this analysis also showed a decrease of $6.5 \%(95 \%$ CI $-9.3 \%$ to $-3.7 \%$ ], Table 3 ) for the younger age group. Between 2004 and 2006, there was a significant decrease in eye examinations by physicians for both age groups.

Overall, our subgroup analyses were consistent with general trends. Between 2004 and 2006, there was no decrease in eye examinations for any subgroup among Ontario residents aged 65 years and older, but there was a significant decrease in eye examinations for all subgroups among Ontario residents aged $40-65$ years. Men aged 40-65 years had fewer eye examinations than women in the same age group, and residents of major urban areas had slightly fewer examinations than people living in nonmajor urban or rural areas; these differences persisted with time (data not shown). Full results of the segmented regression are presented in Appendix 1.

\section{Interpretation}

We found a marked and persistent decrease in publicly funded eye examinations for residents of Ontario with diabetes aged 40-65 years after routine eye examinations were delisted from OHIP for healthy adults in that age group. This trend was seen even though examinations continued to be insured for these patients. We saw no such change for residents of Ontario aged 65 years and older, an age group not affected by delisting.

The decision to delist routine eye examinations for healthy adults in Ontario was made ostensibly to reduce public expenditure on nonessential health services; however, it had the unintended consequence of reducing appropriate use of publicly funded health services. This result was likely due to a misunderstanding of the policy among both patients and providers. Other researchers have also found that attempts to reduce inappropriate use can have unintended consequences. A US study found that an insurance copayment reduced both inappropriate and appropriate use of preventive health services. ${ }^{17} \mathrm{In}$ Quebec, the introduction of cost-sharing for prescription drugs for older adults and recipients of welfare was followed by reductions in use of essential drugs and an increase in related adverse events. $^{18}$

We found a steady decline in physician (mostly ophthalmologist) eye examinations from 1998 to 2010 in both age groups. In contrast, eye examinations performed by optometrists increased from 1998 to 2004 and continued to climb thereafter for people aged 65 years and 
older, but decreased for people aged 40-65 years after the service was delisted. Our findings suggest that, over time, optometrists are likely playing a larger role in retinopathy screening for adults with diabetes. Published data from Alberta also show a gradual decline in ophthalmologic eye examinations over the last decade; unfortunately, data on optometry examinations are not included. ${ }^{15}$

It is unclear why examinations by optometrists decreased for people with diabetes aged 40-65 years after the service was delisted. One possibility is a misunderstanding of the policy among some health care providers and the public who thought eye examinations were no longer covered, even for patients with diabetes. This misinterpretation could have resulted in a decrease in optometry referrals and self-referrals. Alternatively, optometrists may not have been routinely asking patients if they have diabetes, and were thus either inadvertently charging for a service that was publicly covered or billing inappropriately. Any of these explanations is cause for concern. Eye examinations by physicians were unaffected by delisting, perhaps because patients under the care of ophthalmologists are more likely to have greater eye pathology. As a result, a diagnosis of diabetes is less likely to be overlooked, and examinations are less likely to be misclassified as "routine." Ophthalmologists could also continue to bill OHIP a consultation fee for referrals received from a family physician.

Surprisingly, we found a reversal of the income gradient for eye examinations in the 40 64 years age group after delisting, with people in the highest income quintiles having the largest decrease in publicly funded eye examinations. This observation is likely explained by more people in the highest income quintile paying for the service out-of-pocket or through private insurance, suggesting a differential effect of delisting related to income. This hypothesis is consistent with a recent study that found substantially decreased self-reported use of eye care providers among socially disadvantaged residents of Ontario after delisting. ${ }^{19}$ However, the authors did not specifically examine data relating to people with diabetes. Another study found that delisting in other Canadian provinces reduced the probability of patients visiting an optometrist, but that people with supplemental insurance were more likely to use optometry services. ${ }^{11}$

\section{Limitations}

We used routinely collected administrative data, which does not include information on eye examinations paid for out-of-pocket or through private insurance. Furthermore, our study's observational design cannot definitively address causation. However, alternative explanations for the decrease in eye examinations are unlikely for the following reasons: the decrease in eye examinations among people with diabetes aged 40-65 years occurred immediately after the service was delisted, was not seen among people aged 65 years and older, and did not occur for other diabetes tests during the same period. In addition, the marked decrease in diabetes eye examinations that we saw in Ontario after 2004 was not seen in other provinces, such as Alberta ${ }^{15}$ or Manitoba (Alan Katz, Departments of Community Health Sciences and Family Medicine, University of Manitoba, and Associate Director, Manitoba Centre for Health Policy, personal

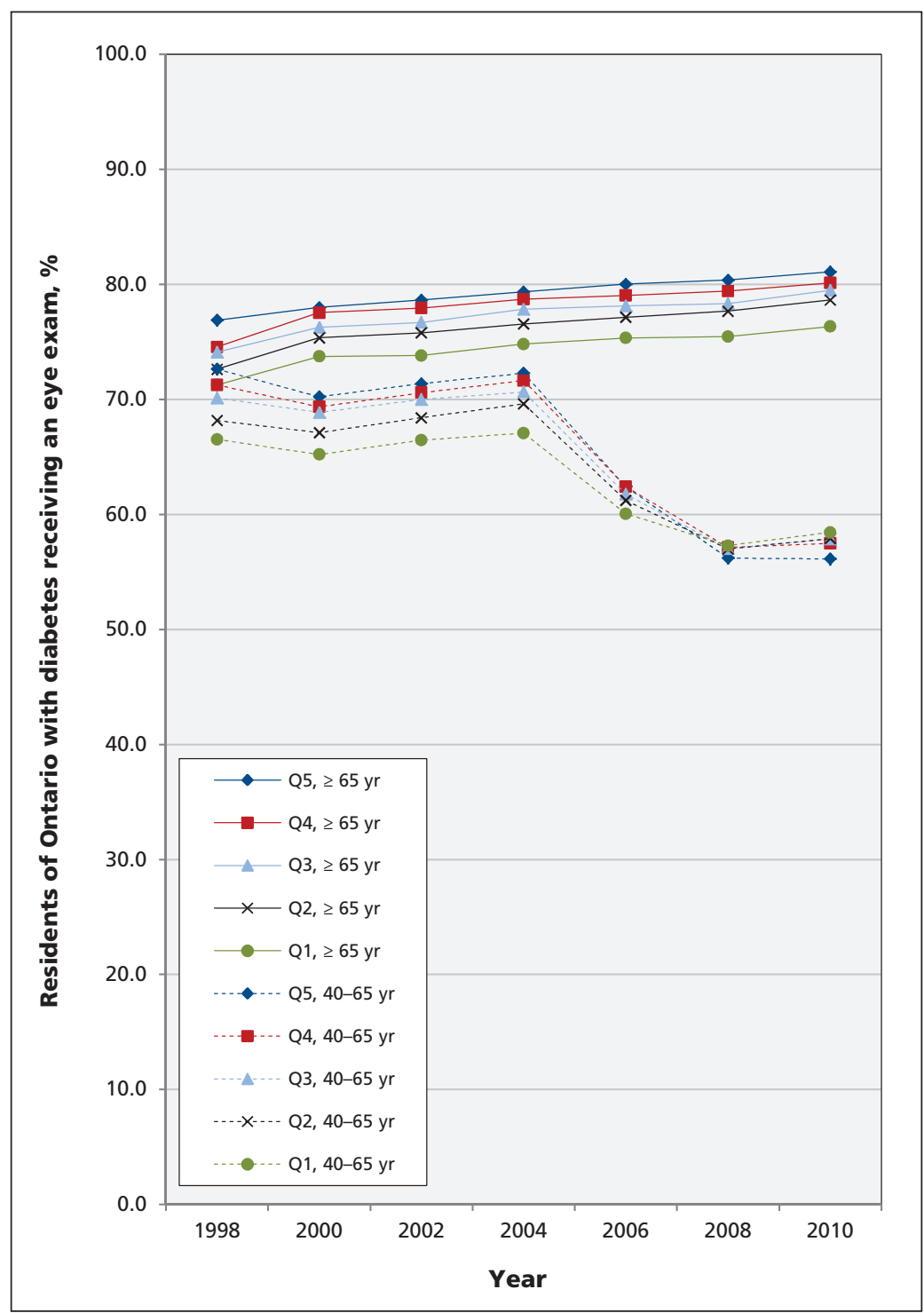

Figure 3: Percentage of Ontario residents with diabetes, by age group and income quintile, who received an eye examination within a 2-year period from 1998 to 2010. Note: Q1-Q5 = income quintiles, Q1 = lowest income quintile, Q5 = highest income quintile. 
Table 3: Changes in testing trends among Ontario residents with diabetes, by age group, before and after routine eye exams were delisted from the provincial public insurance plan

\begin{tabular}{|c|c|c|c|c|}
\hline \multirow[b]{3}{*}{ Variable } & \multicolumn{4}{|c|}{ Age group, yr } \\
\hline & \multicolumn{2}{|c|}{$40-65$} & \multicolumn{2}{|c|}{$\geq 65$} \\
\hline & $\begin{array}{c}\text { Change in trend } \\
2002-2004, \%(95 \% \mathrm{Cl})\end{array}$ & $\begin{array}{c}\text { Change in trend } \\
\text { 2004-2006, \% }(95 \% \mathrm{Cl})\end{array}$ & $\begin{array}{c}\text { Change in trend } \\
2002-2004, \%(95 \% \mathrm{Cl})\end{array}$ & $\begin{array}{c}\text { Change in trend } \\
\text { 2004-2006, \% }(95 \% \mathrm{Cl})\end{array}$ \\
\hline \multicolumn{5}{|l|}{$\begin{array}{l}\text { Overall rates of } \\
\text { recommended } \\
\text { testing* }\end{array}$} \\
\hline Eye examinations & 1.1 (-1.4 to 3.6$)$ & $-8.7(-11.2$ to -6.3$)$ & 0.5 ( -1.3 to 2.3$)$ & $0.6 \quad(0.0$ to 1.3$)$ \\
\hline Cholesterolt & $3.9 \quad$ (0.2 to 7.7$)$ & $2.3 \quad$ (1.0 to 3.6$)$ & 4.2 (3.5 to 4.8 ) & 2.0 (1.8 to 2.1$)$ \\
\hline $\mathrm{HbA} 1 \mathrm{C}$ & 0.6 (-1.1 to 2.4$)$ & $0.8 \quad(0.2$ to 1.5$)$ & $2.4 \quad(0.7$ to 4.1$)$ & 2.4 (1.86 to 3.0$)$ \\
\hline \multicolumn{5}{|l|}{ Rates by provider } \\
\hline Optometry visit & 5.5 (-8.7 to 19.6$)$ & $-6.5(-18.1$ to 5.1$)$ & 4.6 (3.0 to 6.2$)$ & 3.2 (2.6 to 3.7$)$ \\
\hline $\begin{array}{l}\text { Optometry visit, } \\
\text { secondary analysis }\end{array}$ & $4.0 \quad(0.5$ to 7.6$)$ & $-6.5 \quad(-9.3$ to -3.7$)$ & 4.6 (3.0 to 6.2$)$ & 3.2 (2.6 to 3.7$)$ \\
\hline Physician visit only & -4.1 (-9.4 to 1.2$)$ & $-2.3 \quad(-4.2$ to -0.4$)$ & $-4.1(-7.3$ to -0.8$)$ & $-2.6(-3.8$ to -1.4$)$ \\
\hline \multicolumn{5}{|l|}{$\begin{array}{l}\text { Rates by population } \\
\text { subgroup }\end{array}$} \\
\hline Men & 1.0 (-1.1 to 3.2$)$ & $-8.0(-10.1$ to -5.9$)$ & 0.6 (-1.3 to 2.5$)$ & $0.6(-0.1$ to 1.3$)$ \\
\hline Women & 1.2 (-1.9 to 4.4$)$ & $-9.6(-12.7$ to -6.6$)$ & $0.5(-1.2$ to 2.2$)$ & 0.6 (0.0 to 1.2$)$ \\
\hline \multicolumn{5}{|l|}{ Income quintile } \\
\hline 1 (lowest) & 1.0 (-1.2 to 3.2$)$ & $-6.9 \quad(-9.1$ to -4.8$)$ & $0.6(-1.7$ to 2.8$)$ & $0.5(-0.3$ to 1.3$)$ \\
\hline 2 & $1.7(-0.4$ to 3.8$)$ & $-8.6(-10.6$ to -6.5$)$ & 0.3 (-2.0 to 2.6$)$ & $0.7(-0.1$ to 1.5$)$ \\
\hline 3 & 1.1 (-1.0 to 3.2$)$ & $-9.2(-11.2$ to -7.2$)$ & 0.6 (-1.4 to 2.7$)$ & $0.5(-0.2$ to 1.3$)$ \\
\hline 4 & 1.6 (-1.7 to 4.2$)$ & $-9.6(-12.4$ to -6.7$)$ & 0.3 (-2.0 to 2.7$)$ & $0.4(-0.4$ to 1.3$)$ \\
\hline 5 (highest) & 1.0 (-2.7 to 4.7$)$ & $-10.4(-14.0$ to -6.8$)$ & $0.6 \quad(0.2$ to 1.1$)$ & $0.5 \quad$ (0.4 to 0.7$)$ \\
\hline \multicolumn{5}{|l|}{ Residence } \\
\hline Major urban & $1.2(-1.4$ to 3.8$)$ & $-9.1(-11.6$ to -6.6$)$ & 0.4 (-1.4 to 2.4$)$ & $0.5(-0.1$ to 1.2$)$ \\
\hline Nonmajor urban & 0.9 (-0.7 to 2.6$)$ & $-7.8 \quad(-9.4$ to -6.2$)$ & 0.8 ( -1.0 to 2.6$)$ & $0.7 \quad(0.0$ to 1.3$)$ \\
\hline Rural & 1.0 (-2.2 to 4.3$)$ & $-7.1(-10.2$ to -3.9$)$ & $0.6(-1.6$ to 2.9$)$ & $0.6(-0.2$ to 1.5$)$ \\
\hline $\begin{array}{l}\text { Note: } \mathrm{HbA} 1 \mathrm{C}=\text { glycated he } \\
\text { *Recommendations are for } \\
\text { †Time converted to log sca } \\
\text { †Rates for people aged } 40\end{array}$ & $\begin{array}{l}\text { bin. } \\
\text { examination, } 1 \text { cholesterol }\end{array}$ & $\begin{array}{l}\text { d } 4 \text { HbA1C tests in } 2 \text { years. } \\
\text { ow approximation of linear } \\
\text { oximation of a linear trend b }\end{array}$ & 2004. & \\
\hline
\end{tabular}

communication), so it is less likely to be explained by secular trends (Alberta delisted eye examinations for middle-aged adults in 1995, and Manitoba did the same in 1996).

\section{Conclusion}

Although eye examinations for people with diabetes aged 40-65 years continue to be covered by OHIP, we saw a significant and persistent decrease in their use among such patients. More research is needed to understand what proportion of diabetes eye examinations are paid for privately, whether disadvantaged residents of Ontario have decided to forgo these examinations entirely because of cost, and whether the decrease in screening was associated with an increase in retinal complications for people with diabetes. People with lower educational attainment are less likely to visit an ophthalmologist $\mathrm{t}^{20}$ and research is needed to understand whether delisting has exacerbated such inequities.

In this time of fiscal restraint, policy-makers will increasingly debate which services are "medically necessary" and warrant coverage. ${ }^{21}$ Some limitations of services may be rational and justified, ${ }^{22}$ but policy-makers will need to be mindful of the unintended consequences of delisting services from insurance schemes and the potential impact on health equity. Policy changes need to be accompanied by better and more effective communication strategies to decrease misunderstanding among patients and health care providers. 


\section{References}

1. Mohamed Q, Gillies MC, Wong TY. Management of diabetic retinopathy: a systematic review. JAMA 2007;298:902-16.

2. Kempen $\mathrm{JH}$, O'Colmain B, Leske M, et al. The prevalence of diabetic retinopathy among adults in the United States. Arch Ophthalmol 2004;122:552-63.

3. Ferris FL. How effective are treatments for diabetic retinopathy? JAMA 1993;269:1290-1.

4. Cheung N, Mitchell P, Wong TY. Diabetic retinopathy. Lancet 2010;376:124-36.

5. American Diabetes Association. Executive summary: standards of medical care in diabetes. Diabetes Care 2012;35(Suppl 1):S4-10.

6. Canadian Diabetes Association Clinical Practice Guidelines Expert Committee. Canadian Diabetes Association 2008 clinical practice guidelines for the prevention and management of diabetes in Canada. Can J Diabetes. 2008;32:S1-201.

7. Ontario Ministry of Health and Long Term Care. Ministry programs: Ontario Health Insurance Plan (OHIP) eligibility. Toronto (ON): The Ministry; 2009. Available: www.health.gov. on.ca/en/public/programs/ohip/ (accessed 2012 July 20).

8. Ontario Ministry of Health and Long-Term Care. OHIP Bulletin 8089: changes to eye care services for patients age 20 to 64 years. Toronto (ON): The Ministry; 2004.

9. Ontario Association of Optometrists. What is an eye exam? Mississauga (ON): The Ministry. Available: www.optom.on.ca/for _patients/what_is_an_optometrist/what_is_an_eye_exam (accessed 2012 July 20).

10. Ontario Medical Association. Physicians guide to third party billing and other uninsured services. Toronto $(\mathrm{ON})$ : The Association; 2007.

11. Stabile M. The effects of de-listing publicly funded health care services. In: Beach C, Chaykowski R, Shortt S, et al., editors. Health services restructuring in Canada: new evidence and new directions. Kingston (ON): John Deutsch Institute for the Study of Economic Policy, McGill/Queen's University Press; 2006. p. 83-110.

12. Ferguson R. Cuts to OHIP services could include some planned c-section births. Toronto Star 2012 Jan. 25.

13. Hux JE, Ivis F, Flintoft V, et al. Diabetes in Ontario: determination of prevalence and incidence using a validated administrative data algorithm. Diabetes Care 2002;25:512-6.

14. Kralj B. Measuring "rurality" for purposes of health-care planning: an empirical measure for Ontario. Toronto $(\mathrm{ON})$ : Ontario Medical Association; 2005

15. Rudnisky C, Tennant MTS, Johnson JA, et al. Diabetes and eye disease in Alberta. In: Johnson JA, editor. Alberta diabetes atlas 2011 Edmonton (AB): Institute of Health Economics; 2011. p. 141-62.

16. Wagner AK, Soumerai S, Zhang F, et al. Segmented regression analysis of interrupted time series studies in medication use research. J Clin Pharm Ther 2002;27:299-309.

17. Lohr KN, Brook RH, Kamberg CJ, et al. Use of medical care in the Rand Health Insurance Experiment. Diagnosis- and servicespecific analyses in a randomized controlled trial. Med Care 1986;24(Suppl 9):1-87.

18. Tamblyn R, Laprise R, Hanley JA, et al. Adverse events associated with prescription drug cost-sharing among poor and elderly persons. JAMA 2001;285:421-9.
19. Jin YP, Buys YM, Hatch W, et al. De-insurance in Ontario has reduced use of eye care services by the socially disadvantaged. Can J Ophthalmol 2012;47:203-10.

20. Glazier RH, Agha MM, Moineddin R, et al. Universal health insurance and equity in primary care and specialist office visits: a population-based study. Ann Fam Med 2009;7:396-405.

21. Charles C, Lomas J, Giacomini M. Medical necessity in Canadian health policy: four meanings and ... a funeral? Milbank $Q 1997$; 75:365-94.

22. Brody H. From an ethics of rationing to an ethics of waste avoidance. N Engl J Med 2012:366;1949-51.

Affiliations: From the Keenan Research Centre in the Li $\mathrm{Ka}$ Shing Knowledge Institute (Kiran, Glazier), and the Department of Family and Community Medicine (Kiran, Glazier), St. Michael's Hospital, Toronto, Ont.; the Department of Family and Community Medicine (Kiran, Moineddin, Glazier), the Dalla Lana School of Public Health (Moineddin, Victor), and the Department of Medicine (Shah), University of Toronto, Toronto, Ont.; the Institute for Clinical Evaluative Sciences (Kopp, Moineddin, Victor, Campbell, Shah, Glazier), Toronto, Ont.; the Department of Ophthalmology (Campbell), Queen's University, Kingston, Ont.; the Department of Ophthalmology (Campbell), Hotel Dieu Hospital, Kingston, Ont.; and the Department of Medicine (Shah), Sunnybrook Health Sciences Centre, Toronto, Ont.

Contributors: Tara Kiran and Richard Glazier conceived the idea for the study. All of the authors made substantial contributions to the study design. Tara Kiran, Alexander Kopp, Charles Victor and Rahim Moineddin analyzed the data. Tara Kiran, Rahim Moineddin, Robert J. Campbell, Baiju R. Shah and Richard Glazier interpreted the data. Tara Kiran drafted the manuscript, and all of the authors critically reviewed it for important intellectual content. All of the authors approved the final version submitted for publication.

Funding: This study was supported by the Institute for Clinical Evaluative Sciences (ICES), which is funded by an annual grant from the Ontario Ministry of Health and Long-Term Care (MOHLTC). The opinions, results and conclusions reported in this paper are those of the authors and are independent from the funding sources. No endorsement by ICES or the Ontario MOHLTC is intended or should be inferred.

Acknowledgements: Tara Kiran is supported by a New Investigator Award from the Department of Family and Community Medicine, University of Toronto. The authors thank Jeffrey Johnson for providing them with permission to reproduce published data from Alberta and Alan Katz for sharing data from Manitoba. The authors thank Mark Stabile for his comments on the manuscript. 